\title{
KAHNEMAN'S THINKING FAST AND SLOW: FROM BESTSELLER TO TEXTBOOK
}

THINKING, FAST AND SLOW

By Daniel Kahneman. New York: Farrar, Straus and Giroux, 2011. 499 p.

Thinking, fast and slow is an international bestseller and already a classic. It can be a behavioral economics textbook, too. I have tried and it worked. I have broken the book into five parts, each of which I will address in turn. I will not provide exhaustive details of the chapters; these can be found elsewhere in the notes compiled by Jane Sigford (available on http://www.academia.edu/5787896/Book-notesthinking-fast-andslow).

Part I covers the two systems that are supposedly in charge of our mind and drive the way we think. System 1 is fast and intuitive; System 2 is slower and more deliberative. In the first nine chapters, Kahneman offers a world class survey of the recent developments in cognitive psychology, which can be useful for economics, finance, and marketing. Here, Kahneman successfully accommodates the work of his entire career within the two-system framework. His work with Amos Tversky garnered Kahneman the 2002 Nobel Prize in Economics (Tversky died in 1996 of skin cancer). (You can get a flavor of Part I by watching online the YouTube video on https://www.youtube.com/ watch?v=cthixo70SA8.)

I was in charge of a behavioral economics course last year, and experimentally adopted Kahneman's book. Each chapter was presented by the students through one-hour PowerPoint presentations. The presentations were then followed by lively debate. What is more, the book's endnotes occupied center stage, as the bibliographical references were made available on the class share site.

Unlike economics, psychology does not neglect its biological basis. However, the field of cognitive psychology is particularly focused on how the mind works without posing why explanations. Meanwhile, why explanations are the realm of evolutionary psychology. For these reasons I find it useful to complement the discussion in the Part I of the book with topics from, for instance, Evolutionary Psychology by David Buss (Boston: Pearson, 2008) if time allows.

Part II (chapters 10 to 18 ) is about heuristics and cognitive biases, which are the core of Kahneman and Tversky's work. Heuristic is a simple procedure that helps find adequate, though often imperfect, answers to difficult questions. The word comes from the same root as eureka. Cognitive biases come from illusions of thought automatically generated by the quick System 1. The major theme is: Why is it so difficult for us to think 
statistically? As Kahneman observes, "we easily think associatively, we think metaphorically, we think casually, but statistics requires thinking about many factors at once, which is something that System 1 is not designed to do" (p.13). There is a psychological law of small numbers which means disregarding the statistical law of large numbers. Mental anchors are discussed and also how cause trumps statistics and how regression to the mean is neglected. Finally, there is a suggestion of how to tame intuitive predictions.

The human mind's limitation to think statistically contributes to overconfidence, the underlying theme of Part III (chapters 19 to 24). Here, Kahneman draws a lot from The Black Swan of Nassim Taleb (New York: Random House, 2007). As Kahneman puts it, we have an excessive confidence in what we believe we know. We usually are unable to acknowledge the full extent of our ignorance. We tend to understate the uncertainty of the world we live in. We are prone to overestimate how much we understand about the world, and to underestimate the role of chance in events. Unfortunately, overconfidence is fed by the illusory certainty of hindsight. The moral of the story: We must learn from past lessons while resisting the appeal of hindsight and the illusion of certainty.

Part IV (chapters 25 to 34 ) is about choice and how economics fails to pay sufficient attention to how choices are made considering the psychological dimension. Kahneman presents expected utility theory and shows its fundamental error. Then he updates his own "prospect theory" bearing in mind the two-system model of current cognitive psychology.
Richard Thaler once suggested a distinction between Humans and Econs (see Nudge by Richard Thaler and Cass Sunstein - New Haven: Yale University Press, 2008). Psychologists study the behavior of Humans, and economists concentrate on Econs, who are rational and selfish, and whose tastes do not change. However, Humans are neither completely rational nor fully selfish, and their tastes are far from being stable. Humans have the two systems of thinking, and Econs have the System 2 only. And psychologis ts seek to understand how Humans make risky choices without assuming rationality. I call your attention for the fact that it was such a perspective that gave rise to the behavioral economics agenda.

The expected utility theory of risky choice assumes that people make decisions rationally and then always choose the option of greater expected value. For prospect theory, which is an alternative to expected utility theory, what really matters is the different reaction to gains and losses rather than the expected result of a choice based on the current state of wealth. Psychologically, the response to losses is more than twice as strong as the response to corresponding gains. This phenomenon is referred to as loss aversion.

Part IV is where the hot topics of behavioral economics step in. Kahneman offers updated overviews of the endowment effect (owning a good appears to increase its value), the disposition effect (in stock trading, a preference for selling winners rather than losers), preference reversals, and the effects of framing in judgment and choice.

The final Part V (chapters 35 to 38 ) is perhaps the most intriguing of all. It des- cribes recent research that has introduced a distinction between two selves, the experiencing self and the remembering self, which do not have the same interests. This matters for the field of happiness economics and the measurement of well-being as it poses a puzzle. How can two selves within a single body pursue happiness? This is troubling for both individuals and public policy which targets well-being.

The remembering self rules the roost. There is duration neglect of a bad experience and useless concentration on a peak-end rule, thanks to the workings of System 1. For instance, you may give the good and the bad part of your experience equal weight, although the good part lasted ten times as long as the other. This is how things work, and this sounds like self-deception. Personally, here I believe there is room for interesting research focusing on the why explanations for self-deception. The biological roots of the two selves can be accommodated within an evolutionary adaptive theory of self-deception, such as the one presented in The Folly of Fools by Robert Trivers (New York: Basic Books, 2011). Why is there a contradiction at the core of our mental lives? As soon as information hits our brains, it often becomes biased and distorted, usually without conscious effort. In short, why does self-deception succeed? Trivers argues that in order to deceive others, we often deceive ourselves first. We selectively recall information and bias our arguments. In summary, Kahneman's book goes beyond hype and may be useful in academia for both teaching and research. 